\title{
Factors associated with improper metered-dose inhaler technique among adults with asthma in a primary care clinic in Malaysia
}

\author{
Nurafiza Binti Mohd Arif, Ping Yein Lee, Ai Theng Cheong, Roshan Nur Anand Ananthan \\ Mohd Arif N, Lee PY, Cheong AT, et al. Factors associated with improper metered-dose inhaler technique among adults with asthma in a primary care \\ clinic in Malaysia. Malays Fam Physician. 2021;16(2);58-66. https://doi.org/10.51866/oa1231
}

\section{Keywords:}

Metered-dose inhaler,

technique, adult, asthma,

primary care setting

\section{Authors:}

Lee Ping Yein

(Corresponding author)

MBBS, MMed Family Med

UM eHealth Unit, Faculty of Medicine

University of Malaya, Kuala Lumpur

Malaysia

Email: pylee02@gmail.com

\section{Nurafiza Binti Mohd Arif}

MD, MMed Family Med

Klinik Kesihatan Putrajaya, Wilayah

Persekutuan Putrajaya, Malaysia

\section{Cheong Ai Theng}

MBBS, MMed Family Med, PhD

Department of Family Medicine,

Faculty of Medicine and Health

Sciences, Universiti Putra Malaysia,

Serdang, Malaysia

\section{Roshan Nur Anand Ananthan} MBBS

Deparment of Family Medicine,

Faculty of Medicine and Health

Sciences, Universiti Putra Malaysia, Serdang, Malaysia

\begin{abstract}
Introduction: Metered-dose inhalers (MDI) are the most used inhalers worldwide. However, improper MDI techniques remain a significant problem and cause uncontrolled asthma. Studies worldwide have reported that the causes of inefficient inhaler technique are multifactorial. However, this topic has been less well studied in the Asian population. This study aimed to evaluate the MDI technique and associated factors among adults with asthma in a primary care setting in Malaysia.
\end{abstract}

Method: This was a cross-sectional study with universal sampling conducted between July and October 2017. A total of 146 patients with asthma aged 18 years and older in a primary care clinic in Putrajaya, Malaysia were recruited. Logistic regressions were used for statistical analysis to examine the association between improper MDI techniques and their related factors.

Results: The majority (83\%) of respondents were female with a median age of 37 (IQR $=30.75-$ 49.25) years, and the median duration of asthma of $20(\mathrm{IQR}=10-30)$ years. An improper MDI technique was observed in 100 (71.9\%) patients. The most frequently missed step was exhaling gently and fully before inhalation (51.4\%). Respondents who were not on an MDI preventer (adjusted OR: 2.487, 95\% CI: 1.121-5.519, $\mathrm{p}=0.025$ ) or had used an MDI 5 years or fewer (adjusted OR: $3.369,95 \%$ CI: $1.425-7.964, \mathrm{p}=0.006$ ) were more likely to employ an improper MDI technique.

Conclusion: There was a high proportion of improper MDI techniques among patients with asthma. Patients not using an MDI preventer or who had used an MDI less than 5 years were at higher risk of improper MDI technique.

\section{Introduction}

Asthma is one of the most common chronic diseases worldwide and its prevalence has increased globally. ${ }^{1}$ In Malaysia, bronchial asthma continues to be one of the most common chronic diseases in adults and children, and it poses a significant disease burden. In 2013, asthma deaths in Malaysia reached 1,642 (1.29\%) of total deaths, and it was the second of the three most deadly chronic respiratory diseases. ${ }^{2,3}$ Around 58\% of asthmatic patients visited the emergency department $\geq 2$ times in 6 months for acute exacerbations, ${ }^{4}$ and $27.3 \%$ of asthmatic patients experienced an average of 6 days loss of work.

One of the causes of uncontrolled asthma is incorrect inhalation technique. ${ }^{6}$ The pressurized metered-dose inhaler (pMDI) is the most prescribed economical inhaler worldwide and Malaysia. ${ }^{7.8}$ However, the
pMDI is the most difficult inhaler to use, and most patients have shown an incorrect inhalation technique. ${ }^{910}$ Patient characteristics that were associated with inefficient inhalation techniques included older age,,$^{11,12}$ being female ${ }^{13,14}$ or widowed, ${ }^{10}$ or having a low education level ${ }^{11,12,15-17}$ or low socioeconomic level. ${ }^{10,17}$ Also, most studies have found that metered-dose inhaler (MDI) users were at risk of making more critical errors compared to dry powder inhaler users. ${ }^{10,16,18,19}$ Using multiple different inhalers also confused patients and put them at risk of developing an improper inhaler technique. ${ }^{20}$ Studies also reported a strong correlation between a good level of asthma knowledge and a proper inhalation technique. ${ }^{21,22}$

To date, study results regarding the proportion of inefficient inhaler techniques in Malaysia and their associated factors have been inconsistent. Two studies found that a 
longer duration of inhaler use was associated with proper inhaler technique but there was no significant association between sociodemographic data and inhaler technique..$^{23,24}$ However, no study comprehensively looked into the association of socio-demographic factors, disease characteristics, and patient attributes with improper MDI techniques, particularly in the primary health care setting. In addition, in the previous studies done locally, the studied populations were from medical or chest outpatient clinics and a primary care clinic located in a hospital. ${ }^{22-24}$

It is known that patients with poor MDI techniques may have poor clinical outcomes. ${ }^{11}$ Therefore, it is essential for physicians and other healthcare providers to explore and understand the issues related to inhaler performance and to identify the difficulties faced by the patients while using it. Hence, by evaluating and identifying the difficulties of inhaler use and the factors associated with incorrect inhaler techniques, this study could help clinicians identify patients at risk of errors in technique and thus lead to better patient education and monitoring. This would result in better asthma control, less unscheduled healthcare resource use, good clinical outcomes, and improved quality of life.

\section{Methods}

A cross-sectional study design was chosen to evaluate MDI techniques and determine the factors associated with improper inhaler techniques among asthmatic patients attending a primary care clinic in Putrajaya, Malaysia. In this study, the risk factors studied were socio-demographic factors, asthma disease and treatment profiles, asthma knowledge profiles, and the outcome was improper MDI techniques.

\section{Participants}

The study population comprised adult asthmatic patients who attended the primary care clinic from July to October 2017. In this clinic, all patients who were on inhalers would receive training on inhaler usage by a trained pharmacist using a standardized guide, with checking and reinforcement by the treating doctor during follow-up. All adult asthmatic patients aged $\geq 18$ years who fulfilled the eligibility criteria were selected. The inclusion criteria were diagnosis of bronchial asthma by a doctor at least 1 year prior and a prescription for an MDI. The study excluded those who smoked $\geq 20$ pack-years or those with other chronic respiratory illnesses such as bronchiectasis and chronic lung disease, asthmatic patients using an MDI with aero chamber or spacer, and those with severe asthma exacerbation that requires resuscitation and hospitalization.

\section{Sample size}

The largest sample size was taken based on the factor "no regular follow-up" in the Zahrani et al. study. ${ }^{21}$ The formula used was the twosample proportion formula. It was calculated at $90 \%$ power of the study and significance level $\alpha$ at 0.05 with a $95 \%$ confidence interval. The calculated sample size was 146 with consideration of $30 \%$ non-respondents.

\section{Study instruments}

The data were collected using a structured questionnaire that had been pretested. The questionnaire had 4 sections: Section A focused on socio-demographic data including age, gender, race, employment status, household income, level of education, and comorbidities. Section B covered the clinical characteristics of asthmatic patients, including the duration of asthma, duration of inhaler use, types of inhalers, and the presence of follow-up. Section C consisted of an evaluation of asthma knowledge using a validated questionnaire. The Asthma Knowledge Questionnaire was developed in Malaysia and validated in the Malay language. ${ }^{25}$ The questionnaire assesses asthma disease and asthma treatment knowledge. The questionnaire is reliable, with an intraclass correlation coefficient value was 0.857 and Cronbach's $\alpha$ value of 0.74 for testretest reliability. The questionnaire comprises 25 questions with answers of either "yes" or "no." Each correct answer gets 1 point with a total possible score of 25 , which is considered $100 \%$. A total score of $\geq 75 \%$ indicates good knowledge, whereas $50-74.9 \%$ is moderate, and $<50 \%$ indicates poor knowledge. Section $\mathrm{D}$ consists of an MDI technique assessment based on "Handling of Inhaler Devices: A Practical Guide for Pharmacists" from Pharmaceutical Services Division, Ministry of Health, Malaysia, a standard guideline used in primary care and tertiary centres in Malaysia. ${ }^{26}$ It consists of 7 steps to be followed. The step "inhalation" includes coordinating the actuation of the MDI and continued inhalation for about 3-5 seconds until the lungs are full. A technique is considered improper if it is missing at least one out of seven steps based on the standard MDI checklist. 


\section{Data collection}

A universal sampling method was used. All adult patients who registered at the outpatient clinic during the study period were screened for the inclusion and exclusion criteria. Written informed consent was obtained from patients who agreed to participate. Data were collected through face-to-face interviews with a structured questionnaire, and MDI technique assessments were done using a standard checklist with a placebo device. Researchers corrected participants who performed improper MDI techniques with demonstrations and training. The completed questionnaire was recollected, followed by verification of the information with medical records and completeness checking.

\section{Statistical Methods}

Descriptive statistics and median and standard interquartile range were used to summarize continuous variables as samples were not normally distributed. The frequencies and proportions were used to summarize categorical variables with a 95\% confidence interval $(95 \% \mathrm{CI})$. For statistical analysis, all variables were recorded in categorical variables; comparisons with dependent variables were performed using chi-square or Fisher exact. The level of significance was set at $\mathrm{p}<0.05$. Univariate logistic regression models were developed using independent variables as predictors for improper MDI technique. The univariate models considered all the available factors (socio-demographic, disease characteristic, and patient factors) with a possible association with an improper MDI technique. Subsequently, the factors with a p-value of less than 0.25 in univariate analysis were included in the multivariate model. ${ }^{27}$ Both univariate and multivariate logistic regression model results were presented as odds ratio (OR) with a 95\% confidence interval. Data were analysed using Statistical Package for the Social Science (SPSS), version 23.0, for Windows.

\section{Results}

There were 146 out of 147 eligible participants recruited for this study with a response rate of $99.3 \%$.

Table 1: Sociodemographic data of the study participants $(N=146)$

\begin{tabular}{lcc} 
Variable & Result N $(\%)$ & Median (IQR) \\
\hline Age, years & & $37(30.75-49.25)$ \\
$<60$ & $133(91.1)$ & \\
$\geq 60$ & $13(8.9)$ & \\
\hline Gender & $99(67.8)$ \\
Female & $47(32.2)$ \\
Male & $144(98.6)$ \\
\hline Race & $0(0.0)$ \\
Malay & $1(0.7)$ \\
Chinese & $1(0.7)$ \\
Indian & \\
Others & $6(4.1)$ \\
\hline Education level & $56(38.4)$ \\
Primary school & $43(29.4)$ \\
Secondary school & $38(26.0)$ \\
Certificate and diploma & $3(2.1)$ \\
Degree & \\
Postgraduate & $12(8.2)$ \\
\hline Employment status & $14(9.6)$ \\
Student & $31(21.2)$ \\
Self-employed & $67(45.9)$ \\
Professional & $6(4.1)$ \\
Non-professional & $16(11.0)$ \\
Pensioner & \\
Unemployed & $64(43.8)$ \\
\hline Household income & $82(56.2)$ \\
$<3000$ & $99(67.8)$ \\
$\geq 3000$ & $26(17.8)$ \\
\hline No. of comorbidities & $21(14.4)$ \\
0 & $22(15.1)$ \\
1 & $19(13.0)$ \\
$\geq 2$ &
\end{tabular}


Table 1 presents the socio-demographic data of the study participants. The study participants were predominantly female $(67.8 \%, \mathrm{n}=99)$ and Malay $(98.6 \%, \mathrm{n}=144)$. The median age was 37(IQR $=30.75-49.25)$ years, and the majority of the respondents were $<60$ years old $(91.1 \%, \mathrm{n}=133)$. A larger proportion of participants had completed secondary school $(38.4 \%, \mathrm{n}=56)$ and worked in the non-professional sector $(45.9 \%, \mathrm{n}=67)$. More than half had a monthly household income of $\geq$ RM3000 (56.2\%, $\mathrm{n}=82)$. Most of them had no comorbidities $(67.8 \%, \mathrm{n}=99)$. Among those who had comorbidities, 22 (46.8\%) of them had hypertension and 19 (40.4\%) of them had diabetes mellitus.

Table 2: Disease characteristic of the study participants $(\mathrm{N}=146)$

\begin{tabular}{lcc} 
Variable & Result N (\%) & Median (IQR) \\
\hline $\begin{array}{l}\text { Duration of asthma (years) } \\
\leq 5\end{array}$ & $20(13.7)$ & \\
$>5$ & $126(86.3)$ & $13(5-20)$ \\
\hline Duration of MDI use (years) & & \\
$\leq 5$ & $38(26.0)$ & \\
$>5$ & $108(74.0)$ & \\
\hline On an MDI preventer & & \\
Yes & $78(53.4)$ \\
No & $68(46.6)$ & \\
\hline No. of inhalers & $118(80.8)$ \\
1 & $28(19.2)$ \\
$>1$ & $59(40.4)$ & \\
\hline Asthma follow-up & $82(56.2)$ & \\
No & $5(3.4)$ & \\
Yes & \\
Not applicable & $2(1.4)$ \\
\hline Asthma knowledge level & $45(30.8)$ \\
Poor knowledge & $99(67.8)$ \\
Moderate knowledge & $41(28.1)$ \\
High knowledge & $105(71.9)$ & \\
\hline Proper MDI technique &
\end{tabular}

a indicates that the patient did not attend follow-up yet after the given appointment date.

Disease characteristics and patient factors of the study participants are shown in Table 2. The median duration of asthma was $20(\mathrm{IQR}=$ 10-30) years, and patients predominantly had asthma more than 5 years $(86.3 \%, \mathrm{n}=126)$. The median duration of MDI use was 13 (IQR =5-20) years, and the majority of them had used it for more than 5 years $(74.0 \%, \mathrm{n}=108)$. Approximately half of the study participants were on MDI preventer $(53.4 \%, \mathrm{n}=78)$, and the majority of them only had 1 type of inhaler (80.8\%, $\mathrm{n}=118)$, an MDI. The rest have more than 1 type of inhaler including Turbuhaler and Accuhaler. The majority had no regular follow-up $(40.4 \%, \mathrm{n}=59)$. Most of the participants showed good asthma knowledge $(67.8 \%, n=49)$. Based on an assessment of the MDI technique, the proportion of improper MDI techniques was $71.9 \%(\mathrm{n}=105)$ and the proper MDI technique was $28.1 \%(\mathrm{n}=41)$.
Figure 1 illustrates that exhale to residual volume is the most frequently missed step in the MDI technique. Table 3 illustrates univariate analysis to assess factors associated with improper MDI techniques. These included employment status, duration of MDI use, asthma follow-up, and "on MDI preventer." Univariate analysis showed that participants who used an MDI for 5 years or less were more likely to have an improper MDI technique (OR: 2.415; 95\% CI: 1.102-5.288, $\mathrm{p}=0.028)$. Besides that, participants who were not on an MDI preventer were more likely to use an MDI improperly (OR: 2.253; 95\% CI: 1.077-4.714, $\mathrm{p}=0.031$ ). No associations were observed connecting other factors to improper MDI techniques. 


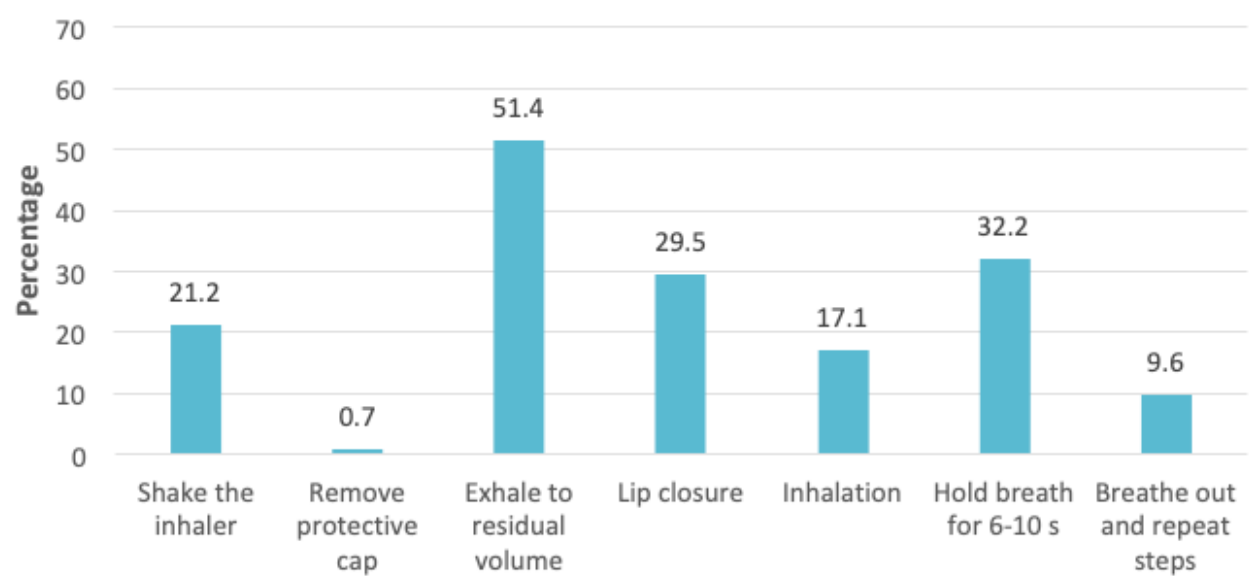

Steps of MDI technique

Missed

Figure 1: Percentage of participants who missed the steps of the MDI technique

Table 3: Unadjusted association between improper MDI techniques and sociodemographic, disease characteristic, and patient factors

\begin{tabular}{|c|c|c|c|c|c|c|}
\hline \multirow{2}{*}{ Factors } & \multirow{2}{*}{ B } & \multirow{2}{*}{ SE } & \multirow{2}{*}{ P-value } & \multirow{2}{*}{$\begin{array}{l}\text { Crude } \\
\text { OR }\end{array}$} & \multicolumn{2}{|c|}{$95 \% \mathrm{CI}$} \\
\hline & & & & & Lower & Upper \\
\hline $\begin{array}{l}<60 \text { years old* } \\
\geq 60 \text { years old }\end{array}$ & 0.521 & 0.603 & 0.387 & $\begin{array}{c}1 \\
1.684 \\
\end{array}$ & 0.517 & 5.486 \\
\hline $\begin{array}{l}\text { Male* } \\
\text { Female }\end{array}$ & 0.353 & .408 & 0.387 & $\begin{array}{c}1 \\
1.423\end{array}$ & 0.640 & 3.166 \\
\hline $\begin{array}{l}\text { Malay* } \\
\text { Non-Malay }\end{array}$ & .956 & 426 & 0.503 & $\begin{array}{c}1 \\
2.600 \\
\end{array}$ & 0.159 & 42.572 \\
\hline $\begin{array}{l}\text { Primary and secondary } \\
\text { school } \\
\text { Certificate and diploma } \\
\text { Degree and above* }\end{array}$ & $\begin{array}{c}-0.091 \\
-0.067 \\
-\end{array}$ & $\begin{array}{c}0.446 \\
0.483 \\
-\end{array}$ & $\begin{array}{l}0.838 \\
0.890 \\
0.979\end{array}$ & $\begin{array}{c}0.913 \\
0.935 \\
1\end{array}$ & $\begin{array}{c}0.381 \\
0.363 \\
-\end{array}$ & $\begin{array}{c}2.188 \\
2.411 \\
-\end{array}$ \\
\hline $\begin{array}{l}\text { Employed* } \\
\text { Student } \\
\text { Unemployed }\end{array}$ & $\begin{array}{c}- \\
-1.437 \\
0.593 \\
\end{array}$ & $\begin{array}{c}- \\
1.066 \\
0.482 \\
\end{array}$ & $\begin{array}{l}0.162 \\
0.177 \\
0.219 \\
\end{array}$ & $\begin{array}{c}1 \\
0.238 \\
1.809 \\
\end{array}$ & $\begin{array}{c}- \\
0.029 \\
0.703 \\
\end{array}$ & $\begin{array}{c}- \\
1.918 \\
4.656 \\
\end{array}$ \\
\hline $\begin{array}{l}\text { Household income } \\
>3000^{*} \\
\text { Household income } \leq 3000\end{array}$ & -0.135 & 0.373 & 0.718 & $\begin{array}{c}1 \\
0.874\end{array}$ & 0.421 & 1.815 \\
\hline $\begin{array}{l}\text { No comorbid* } \\
1 \text { comorbid } \\
\geq 2 \text { comorbids }\end{array}$ & $\begin{array}{c}- \\
-0.068 \\
0.014\end{array}$ & $\begin{array}{r}- \\
0.495 \\
0.532 \\
\end{array}$ & $\begin{array}{l}0.989 \\
0.891 \\
0.979\end{array}$ & $\begin{array}{c}1 \\
0.934 \\
1.014 \\
\end{array}$ & $\begin{array}{r}- \\
0.354 \\
0.357\end{array}$ & $\begin{array}{l}- \\
2.466 \\
2.878 \\
\end{array}$ \\
\hline $\begin{array}{l}>5 \text { years had asthma* } \\
\leq 5 \text { years had asthma }\end{array}$ & 0.376 & 0.510 & 0.460 & $\begin{array}{c}1 \\
1.457\end{array}$ & 0.536 & 3.959 \\
\hline $\begin{array}{l}>5 \text { years used MDI* } \\
\leq 5 \text { years used MDI }\end{array}$ & 0.882 & 0.400 & 0.028 & $\begin{array}{c}1 \\
2.415\end{array}$ & 1.102 & 5.288 \\
\hline $\begin{array}{l}\text { On an MDI preventer* } \\
\text { Not on an MDI preventer }\end{array}$ & 0.812 & 0.377 & 0.031 & $\begin{array}{c}1 \\
2.253\end{array}$ & 1.077 & 4.714 \\
\hline $\begin{array}{l}1 \text { inhaler* } \\
>1 \text { inhaler }\end{array}$ & -0.194 & 0.481 & 0.687 & $\begin{array}{c}1 \\
0.824\end{array}$ & 0.321 & 2.116 \\
\hline $\begin{array}{l}\text { Regular follow-up* } \\
\text { No follow-up }\end{array}$ & 0.464 & 0.377 & 0.218 & $\begin{array}{c}1 \\
1.590 \\
\end{array}$ & 0.760 & 3.325 \\
\hline $\begin{array}{l}\text { Good asthma knowledge* } \\
\text { Poor and moderate asthma } \\
\text { knowledge }\end{array}$ & -0.275 & 0.387 & 0.478 & $\begin{array}{c}1 \\
0.760\end{array}$ & 0.356 & 1.624 \\
\hline
\end{tabular}

* $=$ reference group, $\mathrm{SE}=$ standard error, $\mathrm{CI}=$ confidence interval, $\mathrm{MDI}=$ metered-dose inhaler, $\mathrm{B}=\beta$ coefficient, $\mathrm{OR}=$ odds ratio 
Table 4: Unadjusted association between improper MDI techniques and sociodemographic, disease characteristic, and patient factors

\begin{tabular}{|c|c|c|c|c|c|c|}
\hline \multirow{2}{*}{ Factors } & \multirow{2}{*}{ B } & \multirow{2}{*}{ SE } & \multirow{2}{*}{ P-value } & \multirow{2}{*}{$\begin{array}{c}\text { Crude } \\
\text { OR }\end{array}$} & \multicolumn{2}{|c|}{$95 \% \mathrm{CI}$} \\
\hline & & & & & Lower & Upper \\
\hline Employed* & - & - & 0.176 & Ref & - & - \\
\hline Student & -1.524 & 1.098 & 0.165 & 0.218 & 0.025 & 1.875 \\
\hline Unemployed & 0.605 & 0.530 & 0.254 & 1.832 & 0.648 & 5.182 \\
\hline Used an MDI >5 years* & & & & Ref & & \\
\hline Used an MDI $\leq 5$ years & 1.215 & 0.439 & 0.006 & 3.369 & 1.425 & 7.964 \\
\hline Regular follow- up* & & & & Ref & & \\
\hline No follow-up & 0.318 & 0.410 & 0.438 & 1.374 & 0.616 & 3.068 \\
\hline On an MDI preventer* & & & & Ref & & \\
\hline Not on an MDI preventer & 0.911 & 0.407 & 0.025 & 2.487 & 1.121 & 5.519 \\
\hline
\end{tabular}

* $=$ reference group, $\mathrm{SE}=$ standard error, $\mathrm{CI}=$ confidence interval, $\mathrm{MDI}=$ metered-dose inhaler, $\mathrm{B}=\beta$ coefficient, $\mathrm{OR}=$ odds ratio

Table 4 illustrates the multivariate analysis using multiple logistic regression to determine the predictors of improper MDI techniques after controlling the confounders. Variance inflation factor (VIF) and tolerance statistics were examined to determine the degree of multicollinearity in the model generated to ensure the assumption of multiple logistic regression modelling is met. These tests indicated that the assumption for no multicollinearity was met (mean VIF $=1.02$, tolerance value $>0.9)$. The omnibus model for logistic regression analysis was statistically significant $(\mathrm{p}=0.005)$. Nagelkerke R2 was 0.16 , meaning that $16 \%$ of the data is explained by the model. From the analysis, $75.2 \%$ of subjects were found correctly classified by the model. Besides that, the area under the ROC Curve (AUC) $=0.716,95 \%$ $\mathrm{CI}=0.620-0.813)$, and the Hosmer and Lemeshow test showed that the model was a good fit for the data $(p=0.635)$. These three methods confirmed a good study model that fit the data. The regression model also showed that it fit the observed data well, as Cook's distance values were less than 1 , leverage values fell between 0.02-0.08, standardized residuals were less than 2.39 , studentized residuals were less than 1.97, and DFBeta were less than 0.15. It is evident from Table 4 that using an MDI for less than 5 years (adjusted OR: 3.369, 95\% CI: $1.425-7.964, \mathrm{p}=0.006$ ) and not using an MDI preventer (adjusted OR: 2.487, 95\% CI: 1.121-5.519, $\mathrm{p}=0.025)$ remained significant after controlling for employment status and regular follow-up. We observed no differences in risk by other variables.

\section{Discussion}

This study aimed to evaluate the MDI technique and determine the association between improper MDI techniques and socio-demographic, disease characteristic, and patient factors. We observed a high proportion of improper MDI techniques (71.9\%), with the most frequent being the missed step of exhaling to residual volume (51.4\%). Furthermore, we found an elevated risk of improper MDI techniques in patients using MDI fewer than 5 years. Also, an improper MDI technique was twice as likely among those who were not on an MDI preventer. However, there was no significant association between an improper MDI technique and socio-demographic factors, duration of asthma disease, regular asthma follow-up, and patient factors.

The effectiveness of the MDI device largely depends on the individual's ability to follow the correct inhalation technique. Our study showed a high proportion of adult asthmatic patients $(71.9 \%)$ used their MDI incorrectly although $86.3 \%$ of the respondents had had asthma for more than 5 years. Similarly, through a specially developed computerized device to directly measure four skills associated with good MDI technique, Goodman et al. demonstrated that a high proportion of asthmatic patients used their MDI incorrectly $(75 \%) .{ }^{14}$ In contrast, Loh et al. reported a lower proportion $(40-60 \%)$ of the adult asthmatic population incorrectly using their MDI device as compared to our study. ${ }^{23}$ The differences observed were likely due to less stringent criteria used for defining improper MDI technique. Loh et al. only adopted three obligatory steps (adequate lip closure; slow inhalation with timed pressing; breathholding), whereas our study evaluated seven steps required for a proper MDI technique. There is a lack of consensus regarding the 
methodology to assess MDI errors. Other studies used several different methods such as error cut-off, scoring system, rate of wrong steps, essential steps, or critical errors. ${ }^{11,15,20,24,28}$

Those patients who were not on an MDI preventer or had used an MDI for fewer than 5 years had an increased risk of performing the MDI device technique incorrectly, as evident from our study. No significant association was found linking the duration of asthma disease, regular asthma follow-up, or asthma knowledge with improper MDI technique. A recent cross-sectional study has supported our research that patients receiving inhaled corticosteroid (ICs) as a form of MDI were twice as likely to perform the MDI technique correctly. ${ }^{6}$ It was postulated that giving an MDI ICS together with MDI Salbutamol may reduce confusion in the technique, thus enabling patients to perform the MDI correctly. ${ }^{20}$

It has been demonstrated that the duration of inhaler use was associated with improper inhaler technique..$^{23,24}$ As in previous local studies, our data showed that a longer duration of MDI use was associated with better performance with an MDI device. ${ }^{23,24}$ The cutoffs of 5 and 7 years of MDI use in our study were similar to other studies. This is probably due to an enhanced level of understanding of the device through multiple interactions with physicians and pharmacists. In contrast, some studies found there was no significant correlation between duration of inhaler use and improper MDI technique. ${ }^{6,15}$

Most of the published studies reported no gender differences in inhaler technique, as evident in our study. ${ }^{10-12,15-17,19,21,23}$ In contrast, studies that showed a significant difference between genders, indicating that females were more likely to have an improper MDI technique, except for Gray et al. who found that males were more likely to perform MDI incorrectly. 6,14,19,23,28,29 This might be due to methodological differences, such as Goodman et al. using objective measurements while Chorao et al. used the "rate of wrong steps" to define improper MDI techniques. Also, Gray et al.'s population was different, using a healthy elderly population with little or no exposure to an MDI. Some studies have speculated that females have more difficulty in activating the canister at the right time compared to males. ${ }^{14}$ When considering other socio-demographic factors, our results concur with previous literature that showed no significant difference between socio-demographic factors (e.g., race, education level, household income, comorbidities) and improper MDI technique. ${ }^{19,21,23,24,29,30}$ However, regarding education level and household income, many published studies, including a neighbouring country study (i.e., Thailand) reported that there was a significant association between these factors and improper MDI technique. ${ }^{6,10-12,15,17,31}$ Because our study cohort represented a population with high income and high education level-two factors that previously showed an inverse relationship with improper MDI technique ${ }^{10-12,31}$ —our sample did not include patients with sufficient income or education variability to demonstrate an association between these factors and MDI technique. This differed from the neighbouring country study in which the studied population represented patients largely (85\%) from a low education level. ${ }^{31}$

Patient factors, such as poor asthma knowledge, have been demonstrated to have a positive correlation with improper MDI technique. 22,32 However, we did not demonstrate such an association as supported by the earlier study. ${ }^{30}$ Even though our study evaluated knowledge of the inhaler technique and the majority of participants had high asthma knowledge as a whole, we still did not find any significant association between asthma knowledge and improper MDI technique. This was not surprising as recent studies have revealed a discrepancy between understanding of and confidence in using the inhaler and the practical use of the inhalation device among asthmatic patients. ${ }^{18,28}$

The strength of this study is that we took a practical approach to assess the MDI technique within an urban asthmatic population-a group that is most prevalent in Malaysia. ${ }^{5}$ Assessment of the MDI technique was assessed through visual observation of the patient's demonstration, using checklists based on the standard guideline. This was carried out by a single interviewer to prevent inter-observer variability. However, given the cross-sectional nature of our study, we were unable to assess the causal relationship of the associated factors with improper MDI technique. In the overall asthma knowledge assessment, we did not examine in detail whether there was a lack of asthma knowledge or a lack of MDI technique knowledge. Lastly, these study findings were derived from a single centre and may be 
generalizable to government primary care or other settings with a similar patient profile; however, generalization to other settings may be limited.

In conclusion, this study identified a high proportion of improper MDI techniques among adult patients with asthma in a primary care setting. Patients not on an MDI preventer or who had used an MDI fewer than 5 years were found to have a higher risk of using improper MDI techniques. Technique education and reinforcement are needed periodically in identified groups at risk to improve and maintain the recommended MDI technique among patients with asthma.

\section{Acknowledgment}

We would like to thank all the staff of the clinic who helped with patient recruitment.

\section{Funding}

This work is part of the first author's master research, and it is not funded.

\section{Disclosure of interest}

The authors report no conflict of interest

\section{Ethical Approval}

This study was approved by the Ethics Committee for Research Involving Human Subjects (JKEUPM) and Medical Research Ethics Committee (NMRR-16-1816-32459), Ministry of Health (MOH). Permission from Jabatan Kesihatan Negeri Wilayah Persekutuan was obtained, as this study was carried out within their vicinity. All questionnaires labelled using identification numbers to ensure confidentiality of the data. Written and informed consent was obtained before they participated in the study.

\section{How does this paper make a difference to general practice?}

- Improper metered-dose inhaler (MDI) technique remains a significantly major problem and causes uncontrolled asthma.

- The study found that the prevalence of improper MDI technique was high among patients with asthma in an urban primary care clinic.

- The most frequently missed step in the MDI technique was exhaling gently and fully before inhalation, and patients who were not on an MDI preventer or had used an MDI 5 years or fewer were more likely to employ an improper MDI technique.

- Technique education and reinforcement are needed periodically in identified groups at risk to improve and maintain the recommended MDI technique among patients with asthma.

\section{References}

1. Masoli M, Fabian D, Holt S, et al. The global burden of asthma: Executive summary of the GINA Dissemination Committee Report [Internet]. Allergy: European Journal of Allergy and Clinical Immunology.2004;(59):469-478. [cited 2020 Sep 11] Available from: https:// pubmed.ncbi.nlm.nih.gov/15080825/

2. Omar A, Ganapathy SS, Anuar MFM, et al. Cause-specific mortality estimates for Malaysia in 2013: results from a national sample verification study using medical record review and verbal autopsy. BMC Public Health. 2019 Jan 24;19(1):110. doi: 10.1186/s12889018-6384-7. PMID: 30678685; PMCID: PMC6345029.
3. World Health Organization. Country profile of Environment Burden of Disease. 2019. [Internet] [cited on 2020 Sep 11] Available from: https://www.who.int/quantifying ehimpacts/national/countryprofile/en/

4. Lee PY, Khoo EM. Asthma control and prior medical care of patients presenting with acute asthma at the emergency department. Med J Malaysia. 2003 Nov 1 ;58:482-489.

5. Institute for Public Health (IPH). The Third National Health and Morbidity Survey (NHMS III) 2006. Kuala Lumpur, Malaysia; 2008. [Internet] [cited on 2020 Sep 11] Available from: http://iku.moh.gov.my/ images/IKU/Document/REPORT/2006/ NutritionalStatus.pdf
6. Bartolo K, Balzan M, Schembri EL, et al. Predictors of correct technique in patients using pressurized metered-dose inhalers. BMC Pulm Med. 2017 Feb 28;17(1):47.

7. Thamby SA, Juling P, Xin BTW, et al. Retrospective studies on drug utilization patterns of asthmatics in a government hospital in Kedah, Malaysia. Int Curr Pharm J. 2012 Oct 3;1(11):353-360.

8. Regional Drug and Therapeutic Centre. Cost comparison chart August 2017. 2017. GMMMG. [cited 12 Oct 2020] Available from: http://gmmmg.nhs.uk/docs/formulary/ ch/Ch3-complete.pdf 
9. Hardwell A, Barber V, Hargadon T, et al. Technique training does not improve the ability of most patients to use pressurised metereddose inhalers (pMDIs). Prim Care Respir J. 2011 Jan 11;20(1):92-96.

10. Dalcin P de TR, Grutcki DM, Laporte PP, et al. Factors related to the incorrect use of inhalers by asthma patients. J Bras Pneumol. 2014 Jan;40(1):13-20.

11. Melani AS, Bonavia M, Cilenti V, et al. Inhaler mishandling remains common in real life and is associated with reduced disease control. Respir Med. 2011 Jun 1;105(6):930-938.

12. Sestini P, Cappiello V, Aliani M, et al. Prescription bias and factors associated with improper use of inhalers. J Aerosol Med Depos Clear Eff Lung. 2006;19(2):127-136.

13. Fernando G, De Silva K. Adherence to the National Guidelines on the management of bronchial asthma: a cross-sectional study in Medical Clinics in Teaching Hospital, Karapitiya. Gall Med J. 2010 Nov 12;15(1):8.

14. Goodman DE, Israel E, Rosenberg M, et al. The influence of age, diagnosis, and gender on proper use of metered-dose inhalers. $A m$ J Respir Crit Care Med. 1994;150(5 I):12561261.

15. Hashmi A, Soomro JA, Memon A, et al. Incorrect inhaler technique compromising quality of life of asthmatic patients. J Med. 2012 Mar 6;13(1):16-21.

16. Onyedum C, Desalu O, Nwosu N, et al. Evaluation of inhaler techniques among asthma patients seen in Nigeria: An observational cross sectional study. Ann Med Health Sci Res. 2014;4(1):67.

17. Oliveira PD de, Menezes AMB, Bertoldi $\mathrm{AD}$, et al. Assessment of inhaler techniques employed by patients with respiratory diseases in southern Brazil: a population-based study. $J$ Bras Pneumol. 2014 Sep 1;40(5):513-520.
18. Souza ML de M, Meneghini AC, Ferraz É, et al. Knowledge of and technique for using inhalation devices among asthma patients and COPD patients. J Bras Pneumol. 2009;35(9):824-831.

19. Hesselink AE, Penninx BWJH, Wijnhoven $\mathrm{HAH}$, et al. Determinants of an incorrect inhalation technique in patients with asthma or COPD. Scand J Prim Health Care. 2001;19(4):255-260.

20. Van der Palen J, Klein J, van Herwaarden C, et al. Multiple inhalers confuse asthma patients. Eur Respir J. 1999;14(5).

21. Al-Zahrani JM, Ahmad A, Al-Harbi A, et al. Factors associated with poor asthma control in the outpatient clinic setting. Ann Thorac Med. 2015 Apr 1;10(2):100-104.

22. Sazrina W, Nurliyana $H$, Ryzah $H$, et al. The effect of patients' knowledge on asthma and COPD diseases to Salbutamol metered dose inhaler (MDI) technique. Int J Pharm Res Sch. 2014 Aug 10;3(3):138-145.

23. Loh LC, Teng CL, Teh PN, et al. Metered-dose inhaler technique in asthmatic patients-A revisit of the Malaysian scene. Med J Malaysia. 2004;59(3):335-341.

24. Liam CK, Lo YL, Yap BH, et al. Use of pressurised aerosol inhalers among patients attending the Chest Clinic and Primary Care Department of University Hospital, Kuala Lumpur. Med J Malaysia. 1993;48(3):273-279.

25. Ahmad S, Ismail A, Mohd Zim M, et al. Validation of Malay version of Asthma Knowledge Questionnaire by using classical and modern response theory. Respirology. 2015 Dec;20:17.

26. Rahman EBA, Ismail HB. Handling of inhaler devices: A practical guide for pharmacists. Pharm Serv Div Minist Heal Malaysia. 2010;88. [Internet] [cited on 2020 Sep 11] Available from: https://www.pharmacy.gov. my/v2/sites/default/files/document-upload/ handling-inhaler-devices-practical-guidepharmacists-2011.pdf
27. Bursac Z, Gauss CH, Williams DK, et al. Purposeful selection of variables in logistic regression. Source Code Biol Med. 2008 Dec $16 ; 3(1): 17$.

28. Chorão P, Pereira AM, Fonseca JA. Inhaler devices in asthma and COPD - An assessment of inhaler technique and patient preferences. Respir Med. 2014 Jul 1;108(7):968-975.

29. Gray SL. Characteristics predicting incorrect metered-dose inhaler technique in older subjects. Arch Intern Med. 1996 May 13;156(9):984.

30. Rootmensen G, Van Keimpema A, Jansen H, et al. Predictors of incorrect inhalation technique in patients with asthma or COPD: A study using a validated videotaped scoring method. J Aerosol Med Pulm Drug Deliv. 2010 Oct 1;23:323-328.

31. Pothirat C, Chaiwong W, Phetsuk N, et al. Evaluating inhaler use technique in COPD patients. Int J COPD. 2015 Jul 8;10:12911298.

32. Lurslurchachai L, Krauskopf K, Roy A, et al. Metered dose inhaler technique among innercity asthmatics and its association with asthma medication adherence. Clin Respir J. 2014 Oct $1 ; 8(4): 397-403$ 